\title{
CARNEIRO, Cíntia Braga. O Museu Paranaense e Romário Martins: a busca de uma identidade para o Paraná. Curitiba: SAMP, 2013. 202 p.
}

\author{
Tatiana Takatuzi ${ }^{1}$
}

- Enviado em 27/07/2015

- Aprovado em 17/08/2015

Dos gabinetes de curiosidades a instituições produtoras de conhecimento científico. Ao longo da constituição dos Museus Brasileiros, percebe-se a existência de projetos em que as missões institucionais se fundem e se confundem com as políticas de gestão. Esse é o caso do Museu Paranaense, no período gestado pelo diretor Romário Martins.

O Museu Paranaense foi fundado em 1876, inicialmente como instituição particular, por iniciativa do empresário ervateiro Agostinho Ermelino de Leão e do intelectual João Cândido Muricy. Seis anos mais tarde, em 1882, a instituição foi incorporada ao serviço público do governo da Província do Paraná. Iniciou seu acervo com cerca de 600 peças entre objetos, artefatos indígenas, coleção de moedas e de insetos. Foi o primeiro Museu do Paraná e é o terceiro museu público mais antigo do país.

O livro aqui analisado diz respeito ao papel do Museu Paranaense no processo de construção de uma identidade paranaense durante o período em que Romário Martins foi diretor da Instituição, entre 1902 e 1928. Resultado da dissertação de Mestrado defendida em 2001 no Curso de PósGraduação em História da Universidade Federal do Paraná, a obra foi publicada em versão impressa

\footnotetext{
${ }^{1}$ Graduada em História pela Universidade Federal do Paraná e mestre em Antropologia Social pela Universidade Estadual de Campinas. Atualmente é coordenadora do Setor de História do Museu Paranaense. Endereço eletrônico: ttakatuzi@gmail.com.
} 
e em edição eletrônica ${ }^{2}$, para inaugurar a coleção de Teses do Museu Paranaense, que tem como intuito qualificar a equipe atual e antiga da instituição ${ }^{3}$.

A questão levantada por Cíntia Braga Carneiro é: o museu teria tido uma função importante na difusão da identidade paranaense proposta por Romário Martins e, como este, na posição de diretor, tornou possível esta disseminação? Carneiro responde estas questões de maneira pontual e objetiva, analisando a trajetória do Museu Paranaense, o perfil de Romário Martins como diretor, político e intelectual e o contexto histórico vivenciado.

Para sua análise, a autora utilizou fontes bibliográficas, documentais e periódicos, tais como os jornais "A República”, o "Dezenove de Dezembro", o "Diário da Tarde”, em que buscou analisar o imaginário social e cultural da sociedade paranaense. As publicações do Museu por meio dos boletins "Arquivos do Museu Paranaense", documentos institucionais e correspondências pessoais de Romário Martins também contribuíram para a pesquisa.

Estruturado em quatro capítulos, o livro foi construído em torno da análise sobre a gestão de Romário Martins no Museu Paranaense, observando como seus ideais positivistas e o movimento paranista, tiveram reflexos na Instituição e qual o seu papel na formação da identidade paranaense.

O primeiro capítulo apresenta o cenário nacional de constituição dos primeiros museus brasileiros, como o Museu Nacional, o Museu Emilio Goeldi e o Museu Paulista. Esses estabelecimentos tiveram, na sua gênese, trajetórias similares, destacando-se como espaços voltados à produção de conhecimento científico, tendo à frente das instituições, intelectuais e estudiosos das áreas de história natural ou ciências naturais. De acordo com a autora, essas instituições sempre estiveram voltadas à consolidação da identidade e memória nacional e regional, questão visualizada, sobretudo, por meio das coleções que os museus abrigavam: os estudos na área de ciências naturais legaram coleções de objetos voltados à representação do território, às populações indígenas, aos relatos e coletas dos viajantes naturalistas e, posteriormente, à presença real portuguesa.

O Museu Paranaense também teve uma organização interna semelhante, que se organizava conforme o modelo europeu dos gabinetes de história natural, com seções de zoologia, botânica, geologia, mineralogia, etnologia, arqueologia e antropologia.

\footnotetext{
2 Disponível em:

http://www.museuparanaense.pr.gov.br/arquivos/File/Livros/ebook_museu_paranaense_e_romario_martins.pdf (acessado em 22/07/2015).
}

${ }^{3}$ Cíntia Braga Carneiro fez parte da equipe do Museu Paranaense de maio de 1996 a abril de 2003. 
O contexto de constituição do Museu Paranaense é abordado no segundo capítulo, onde a autora situa a fundação da instituição, seus idealizadores e a elite econômica e social que fez prosperar. O título do capítulo "Paraná: a jovem província em busca de sua identidade" demonstra os esforços empreendidos na recém emancipada quinta comarca em consolidar sua independência política, econômica, social e cultural.

Para Carneiro, o ideal de se construir a identidade paranaense já tinha raízes desde o processo de emancipação política e territorial da então quinta Comarca da Província de São Paulo nas quais as argumentações apoiavam-se nas diferentes características que buscavam ressaltar a qualidade da terra, do clima e os seus produtos típicos, como a erva-mate e o pinheiro.

$\mathrm{Na}$ economia, a produção da erva-mate fez progredir a sociedade e formar uma elite que predominou no cenário econômico e político do Paraná no final do século XIX e início do XX. A burguesia do mate foi responsável pelo investimento em uma série de infra-estruturas como saneamento básico, construção de estradas, escolas, ferrovias, projetos de urbanização, que buscavam tirar o estado da condição de província de São Paulo e, com esse mesmo intuito, construir a identidade do Paraná através de elementos locais, valorizando o território, a paisagem e a história. A preocupação com o espaço urbano e o ambiente cultural também estiveram presentes e pode-se perceber, neste período, a criação de vários estabelecimentos como o Arquivo Público (1855), a Biblioteca Pública (1857), a Escola de Belas Artes e Indústria do Paraná (1866) e o próprio Museu Paranaense (1876).

O discurso intelectual deste período contribuiu enormemente para alavancar os ideais de modernização propagados pela elite ervateira e a figura de Romário Martins foi um dos principais intelectuais a difundir este pensamento. Ao analisar sua biografia, a autora constata a permanência e a propagação deste pensamento ao longo de suas atividades políticas e profissionais.

Desde muito cedo, Romário Martins trabalhou em oficinas de tipografia, passando a atuar como jornalista em muitos jornais de Curitiba, até chegar a ser redator chefe do jornal "A República", imprimindo suas ideias e pensamento nos artigos publicados. Atuou no serviço público na Superintendência do Ensino Público e na Secretaria de Obras Públicas e Colonização. Foi deputado estadual por 10 legislaturas (entre 1904 e 1928), vereador, presidente da Câmara Municipal de Curitiba e prefeito interino em 1905. Entre os anos de 1901 a 1916, empenhou-se à pesquisa da questão de limites entre Paraná e Santa Catarina, produzindo extenso material documental e publicações. Ganhou o título de coronel em 1912 para exercer o cargo de Secretário 
Geral do Comando Superior da Guarda Nacional do Paraná. Como redator do Jornal "A República", pode expressar suas ideias e pensamentos, demonstrando em seus artigos e publicações a preocupação em criar uma identidade, sempre voltados à formação histórica do estado e ao homem paranaense. Seu interesse na história do Paraná também foi bastante marcante no Instituto Histórico e Geográfico do Paraná, no qual foi fundador e membro atuante por muitos anos.

Como diretor do Museu Paranaense, tema do terceiro capítulo do livro de Carneiro, Romário Martins foi nomeado em 1902 e ocupou o cargo por 26 anos. Tamanho prestígio revelava que o museu atendia aos interesses do poder executivo: o de cumprir o seu papel como local de representação de memória e como suporte necessário à construção de uma identidade regional.

Sob forte influência do pensamento positivista, a gestão de Romário Martins no Museu Paranaense foi caracterizada pela organização, classificação e publicação do acervo aos moldes científicos da época. Voltado à construção de uma história nacional, as aquisições do acervo eram pautadas por biografias, genealogias, vultos e grandes eventos históricos, como é possível perceber na coleção da pinacoteca do Museu, formada por personalidades da elite paranaense que viam a doação com finalidade de perpetuar suas memórias na sociedade.

Em sua gestão é possível perceber grandes aquisições de material arqueológico e etnológico, por conta de seu interesse nos povos indígenas e na veiculação do mito do bom selvagem, que tinha a intenção de camuflar os conflitos dos índios com as frentes coloniais.

A autora destaca ainda, a participação de Romário Martins nas exposições nacionais e internacionais que ocorreram no final do século XIX e início do século XX, tema tratado no quarto capítulo do livro. As exposições se constituíram em espaços de exibições de avanços científicos, técnicos e industriais, funcionando para propagandear a sociedade burguesa que tinha como pressupostos básicos o progresso e a civilização. Eram realizadas em datas comemorativas de grande relevância histórica, tal como o Cinquentenário da Província do Paraná, em 1903 (em comemoração à emancipação política do estado) e a Exposição Nacional de 1908 (em comemoração ao primeiro centenário de abertura dos portos do Brasil). Um ano antes desta última exposição, Romário Martins, já então diretor do Museu Paranaense, fez parte da comissão preparatória e usou a instituição como sede para os industriais fazerem suas inscrições e para receberem premiações. O acervo do Museu Paranaense, também foi utilizado nestas ocasiões para divulgação dos produtos, como ocorreu com os trabalhos litográficos da Impressora Paranaense. Era de grande importância a participação do Museu Paranaense nessas exposições, como uma forma de 
organizar suas coleções, pois Romário via uma oportunidade de aumentar o acervo do Museu com objetos e produtos mais destacados da indústria, economia e riquezas naturais paranaenses. Carneiro ressalta que "foi por meio destas exposições que o Museu Paranaense procurou cumprir uma função, criando uma representação do território, por meio da exibição das riquezas naturais do Paraná" ${ }^{4}$. De acordo com a autora, foi um "caminho de mão-dupla", em que Romário produzia suas pesquisas ao mesmo tempo em que divulgava o Museu Paranaense à sociedade paranaense por meio das exposições.

Percebe-se que a direção de Romário Martins, seu discurso intelectual e sua ação política, voltados à construção de uma identidade ao Paraná, tiveram grande influência nos rumos do Museu Paranaense. Em suas obras e artigos publicados é possível visualizar a busca desse intelectual em construir uma identidade regional, manifestando a preocupação pelas coisas do estado. Nas suas atividades políticas ocupava-se com projetos de leis referentes a comemorações e símbolos cívicos, com a devastação de florestas e das riquezas naturais paranaenses.

No livro "O Forjador: ruínas de um mito: Romário Martins", Décio Roberto Szvarça5 , faz uma análise do discurso de Romário Martins em suas obras, apresentando os símbolos e signos construídos por este intelectual, como a representação do pinheiro, a erva mate, a valorização das riquezas naturais e o conceito de civilização do povo paranaense. Estes elementos estavam expressos no movimento paranista, na qual Romário Martins foi o principal idealizador, fundando inclusive o Centro Paranista em 1927. De acordo com Carneiro, o museu funcionou como uma espécie de laboratório para o paranismo, na qual o diretor pôde imprimir suas ideias e projetos.

O paranismo figura como tema corrente nas produções acadêmicas e publicações que dizem respeito à história do Paraná, contudo, análises de Romário Martins à frente das instituições que comandou ainda são escassas. Nesse sentido, o livro de Carneiro possui a peculiaridade de demonstrar a influência desse personagem tão importante para a história do Paraná, numa das instituições culturais mais antigas do país que é o Museu Paranaense. Além disso, a obra resgata um recorte temporal dessa instituição que antes era conhecida apenas por meio de documentos institucionais e notícias de jornais, recuperando parte da sua história e da composição do seu acervo.

\footnotetext{
${ }^{4}$ CARNEIRO, Cíntia Braga. O Museu Paranaense e Romário Martins: a busca de uma identidade para o Paraná. Curitiba: SAMP, 2013, p. 164.

${ }^{5}$ SZVARÇA, Décio Roberto. O forjador: ruínas de um mito: Romário Martins. Curitiba: Aos Quatro Ventos, 1 de jan de 1998 - 123 páginas.
} 